\title{
Modes of Inheritance of Errors of Refraction
}

\section{ARNOLD SORSBY* and BERNARD BENJAMIN $\dagger$}

\begin{abstract}
Summary. Eighteen families in which both parents had refractions within the range of $+4.0 \mathrm{D}$ to $-4.0 \mathrm{D}$ and axial lengths seen in emmetropia (22.3-26.0 mm) showed coefficients of correlation of the order 0.5 indicative of polygenic inheritance. Such coefficients were seen for axial length (0.407) and for the cornea $(0.487)$, but not for the lens (which is known to be yoked to the axial length). No such coefficients were seen in 19 families in which one of the parents had axial length outside the emmetropic range (nine families with long axes and 10 with short axes).

The pattern of polygenic inheritance for emmetropia (completely correlated optical components) and errors of refraction up to 4.0 D (inadequately correlated components: correlation ametropia) follows that seen in stature and other measurable characters. In contrast the high refractive errors with their abnormal axial lengths (component ametropia) are-like the extremes in stature-pathological anomalies with monofactorial inheritance.
\end{abstract}

Studies on twins have shown that all refractions of the eye-emmetropia, hypermetropia, and myopia -are determined genetically (Sorsby, Sheridan, and Leary, 1962; Sorsby and Fraser, 1964). The coefficients of correlation in these different refractive states approached unity in the 78 pairs of uniovular twins studied, 0.5 in the 40 pairs of binovular twins and zero in 48 unrelated control pairs. These findings applied not only to refraction as a whole but also to its individual components: axial length, corneal power, lens power, and depth of the anterior chamber. The actual mode (or modes) of inheritance is still to be assessed and this is attempted in the present analysis.

\section{Material}

The available material consists of two previously reported family studies, one devoted to 21 selected families in which the propositus-either a parent or an offspringshowed unusual refractions, and the other an unselected series of 28 consecutive families presumably representatative of the general population. The basic data and findings on these 49 families are recorded by Sorsby et al (1957) and by Sorsby, Leary, and Fraser (1966).

\footnotetext{
Received 27 November 1972.

* Emeritus Research Professor in Ophthalmology, Royal College of Surgeons, Lincolns Inn Fields, London WC2.

t Director of Studies, Civil Service College, 11 Belgrave Road, London SW1.
}

In the first of these series-the families selected for an unusual refraction in the propositus-the parent/child coefficients of correlation showed no consistent pattern: these were +0.285 for refraction, +0.062 for axial length, +0.271 for corneal power, +0.416 for lens power, and +0.323 for depth of anterior chamber. In contrast four of the five coefficients of correlation in the unselected familes showed fairly high values $(+0.227$ for refraction, +0.314 for axial length, +0.378 for corneal power, and +0.265 for depth of anterior chamber; the coefficient for the lens was only $+0 \cdot 155$ ). Both these groups are used in the present analysis. The material has been re-arranged to contrast the refractions for axial lengths within the range seen in emmetropia $(22 \cdot 3-26.0 \mathrm{~mm})$ with those in which the axial length fell outside this range (ie, short axes of $22.2 \mathrm{~mm}$ or less and long axes of $26.1 \mathrm{~mm}$ or more). So classified the total of 49 families gave 18 families with axial length within the emmetropic range in both parents, 10 with a short axis in a parent and nine with a long axis. Twelve families were excluded: nine in the selected series because the propositus belonged to the filial generation and three in the unselected series because a parent was anomalous in that his axial length fell within the emmetropic range but his refraction was outside the range normally seen with such axes. Table I gives the distribution obtained.

To set out the findings by axial length is warranted by the fact that some $95 \%$ of the population have refractions that (except for a few overlaps) are determined by an axial length that falls within the range $22 \cdot 3-26.0 \mathrm{~mm}$ and 
TABLE I

DISTRIBUTION OF AVAILABLE FAMILIES BY AXIAL LENGTH IN THE PARENTS

\begin{tabular}{l|c|c|c}
\hline & $\begin{array}{c}\text { Unselected Series } \\
\text { (Sorsby } \text { et al, 1966) }\end{array}$ & $\begin{array}{c}\text { Selected Series } \\
\text { (Sorsby } \text { et al, 1957) }\end{array}$ & Total \\
\hline $\begin{array}{l}\text { Both parents show emmetropic } \\
\text { axes }\end{array}$ & 18 & - & 18 \\
\hline One parent shows a short axis & $4^{*}$ & $6^{* *}$ & 10 \\
\hline $\begin{array}{l}\text { One parent shows a long axis } \\
\text { Not usable }\end{array}$ & $3 \dagger$ & $6 \dagger \dagger$ & 9 \\
\hline Total & $3 \ddagger$ & $9 \ddagger \ddagger$ & 12 \\
\hline
\end{tabular}

* Families 3, 7, 14, and 18

+ Families 5, 15, and 23.

$¥$ Families 10, 11, and 21 .

* Families 8, 10,11, 13,16, and 21

t† Families 5, 7, 24, 25, 31, and 37 . (In family 37, both parents showed long axes.)

$\ddagger \ddagger$ Families 1, 2, 3, 6, 16, 26(a), $26^{(\mathrm{b})}$, and 27 .

that the rest have axial lengths outside these limits (they may be as low as $19.2 \mathrm{~mm}$ or as high as $36.0 \mathrm{~mm}$ ). The first group is fairly equally divided between emmetropes and those with hypermetropia or myopia up to $4.0 \mathrm{D}$; in emmetropia the axial length is fully correlated to the powers of the cornea and the lens, whilst refractive errors up to $4.0 \mathrm{D}$ result from various degrees of less adequate correlation (correlation ametropia). In the second group high myopia or high hypermetropia is present and this is determined not by a failure of correlation, but by an anomalous optical component (component ametropia)-almost always the axial length, and very occasionally by an anomalous lens or cornea (Sorsby et al, 1957; Sorsby et al, 1960; Sorsby, Leary, and Richards, 1962).

\section{Analysis}

Table II shows the parent/child coefficients of correlation for the 28 unselected families as a whole set against the recalculated values after excluding the seven families with anomalous axial length and the three with anomalous refraction. It will be seen that in the residual 18 families, the two major com-

TABLE II

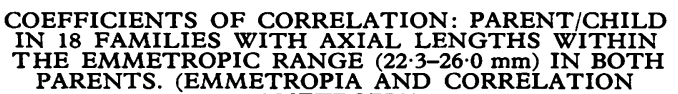
PARENTS ROPIC RANGE $(22 \cdot 3-26 \cdot 0 \mathrm{~mm})$ IN BOT AMETROPIA)

\begin{tabular}{l|c|c}
\hline & $\begin{array}{c}\text { Original 28 } \\
\text { Unselected } \\
\text { Families }\end{array}$ & $\begin{array}{c}\text { Residual 18 } \\
\text { Families* }\end{array}$ \\
\hline Refraction & +0.227 & +0.061 \\
Axial length & +0.314 & +0.407 \\
Corneal power & +0.378 & +0.487 \\
Lens power & +0.155 & +0.096 \\
Anterior chamber: depth & +0.265 & +0.145 \\
\hline
\end{tabular}

* Ten families were excluded (see text). ponents of refraction-axial length and corneal power-now show a considerable shift towards a coefficient of 0.5 expected for determination by a number of genes without dominance; no such shift is however seen for the lens and anterior chamber nor for the overall refraction.

The pattern is strikingly different for the 19 families with anomalous axial lengths. This can be seen from the data in Table III. Except for one parameter-lens power in families with short axesnone of the correlation coefficients are statistically significantly different from zero.

TABLE III

COEFFICIENTS OF CORRELATION: PARENT/CHILD IN 19 FAMILIES WITH ANOMALOUS AXIAL LENGTHS IN ONE PARENT. (COMPONENT AMETROPIA)

\begin{tabular}{|c|c|c|}
\hline & $\begin{array}{l}\text { Ten Families with } \\
\text { Short Axes } \\
(22 \cdot 2 \mathrm{~mm} \text { or less })\end{array}$ & $\begin{array}{l}\text { Nine Families with } \\
\text { Long Axes* } \\
(26 \cdot 1 \mathrm{~mm} \text { or more) }\end{array}$ \\
\hline $\begin{array}{l}\text { Refraction } \\
\text { Axial length } \\
\text { Corneal power } \\
\text { Lens power } \\
\text { Anterior chamber: depth }\end{array}$ & $\begin{array}{c}+0.279 \\
+0.157 \\
+0.211 \\
+0.438 \\
\text { Not known }\end{array}$ & $\begin{array}{c}-0.021 \\
+0.017 \\
+0.167 \\
+0.255 \\
\text { Not known }\end{array}$ \\
\hline
\end{tabular}

* Long axes in both parents in one of the families.

\section{Discussion}

The coefficients of correlation in Table II and III suggest that refractions determined by axial lengths within the emmetropic range (emmetropia and correlation ametropia) are inherited in a polygenic manner and that this mode of inheritance does not apply to refraction with axes outside the emmetropic range (component ametropia). Both these findings call for further consideration. 
Polygenic Inheritance in Refractions Determined by Axes within the Emmetropic Range

Axial Length. The correlation coefficient of +0.407 for the axial length falls short of the expected value of +0.50 but the shortfall is not statistically significant.

Cornea. The correlation coefficient of +0.485 for the cornea satisfies the expected value of 0.5.

Lens. A low correlation coefficient for the lens is to be expected when it is borne in mind that in general the optical components of the eye tend to correlate to emmetropia. The parent/child correlation of lens will thus depend upon the parent/child correlation of cornea and axial length in combination and will obviously be considerably less than 0.5 . With the power of the lens largely determined by axial length (in the 194 eyes studied by Sorsby $e t$ al, 1957, the correlation of axial length/lens was -0.488 ) one would expect a parent/child correlation of lens of less than $0 \cdot 25$.

Anterior Chamber. The low correlation coefficient for the anterior chamber is probably explicable in the same way as is that for lens power. In any case the depth of the anterior chamber is influenced by age and plays little part in refraction.

Refraction. That the coefficient for refraction as a whole is not statistically significantly different from zero is of course to be expected. Since the total refractive power is itself a correlation combination of all the optical components, there clearly could not be a simple parent/child correlation no matter how well the individual components conform to polygenic inheritance.

As emmetropia and correlation ametropia are seen in some $95 \%$ of the population it is clear that polygenic inheritance is the normal pattern in refraction. It would appear that there are two polygene systems, one for axial length and the other for the cornea, and that these are correlated towards emmetropia with finer correlation being provided by the lens, the power of which is largely yoked to the polygenetically determined axial length.

Modes of Inheritance in Refractions Determined by Axes outside the Emmetropic Range

The lack of any significant parent/child correlation coefficients for refraction in the 19 families with anomalous axial length in one of the parents (except for the high correlation of the lens value seen with short axes-and this needs confirmation from larger series) does not of course mean that these refractions are not genetically determined. The evi- dence for twins is conclusive that they are so determined. As regards the mode of inheritance, monofactorial transmission is most likely.

\section{The Available Literature}

The genetic literature on refraction is recorded elsewhere (Sorsby, 1970). Two factors that have led to confusion need to be stressed.

1 The immense literature on the inheritance of myopia and the only slightly smaller literature on the inheritance of hypermetropia has overlooked the pertinent problem of the inheritance of emmetropia and has ignored the facts stressed here that almost all myopes and hypermetropes of up to $4.0 \mathrm{D}$ have axes within the emmetropic range, and that emmetropia and correlation ametropia constitute the bulk of refractions. In taking all myopes together and all hypermetropes together-whether due to faulty correlation or anomalous axial length-any monofactorial pattern would be blurred by the high proportion of polygenetically determined refractions with emmetropic axial lengths in such material.

2 There is considerable evidence in the literature that the higher degrees of myopia and hypermetropia are inherited in a monofactorial manner. The tendency has been to regard them as exceptions rather than of the rule.

The literature on the inheritance of refractive errors contains many pedigrees illustrative of recessive, dominant, and sex-linked inheritance. If only because the lower degrees of myopia and hypermetropia are common in the general population, many of the most convincing pedigrees are those that record high myopia or high hypermetropia. Pedigrees beyond question are those that record the association of high myopia with night blindness as a recessive sex-linked disorder and these go back to Worth in 1906 and Nettleship in 1912; an autosomal recessive for these associated lesions is also known from the extensive pedigree recorded by Gassler in 1925 from Switzerland. Autosomal recessive inheritance probably applies to most high myopia, though dominant transmission is also well documented. It is likely that the inheritance of myopia due to anomalous axial length repeats the pattern seen in retinitis pigmentosa; this is commonly recessive with dominant and sex-linked varieties contributing a relatively small minority of cases. At present there is no evidence for a sex-linked form of high hypermetropia; the available pedigrees show only autosomal inheritance, recessive or dominant.

Clearly, further studies are needed on the inheritance of refractive errors, and these have to be related to measured axial lengths. The range of 
refractions between $+4.0 \mathrm{D}$ and $-4.0 \mathrm{D}$ (emmetropia and the correlation ametropia) is probably the counterpart of the range of measurements in normal stature; both are determined polygenetically. In contrast the component ametropias-high myopia and high hypermetropia, like giants and dwarfs, are outside the normal range: they are pathological in character and monofactorial in inheritance. In biological terms emmetropia and correlation ametropia are continuous variations, and component ametropia is discontinuous. With the necessary techniques for measuring the components of refraction and the available evidence on the hereditary character of all refractions, genetic studies along clearly defined lines are now possible.
REPERENCES
Sorsby, A. (1970). Ophthalmic Genetics, 2nd edition. Butterworths, London.

Sorsby, A., Benjamin, B., Davey, J. B., Sheridan, M., and Tanner, J. M. (1957). Emmetropia and its Abberations. Medical Research Council Special Report Series, No. 293. HMSO, London. Sorsby, A. and Fraser, G. R. (1964). Statistical note on the components of ocular refraction in twins. Fournal of Medical Genetics, 1, 47-49.

Sorsby, A., Leary, G. A., and Fraser, G. R. (1966). Family studies in ocular refraction and its components. fournal of Medical Genetics, 3, 269-273.

Sorsby, A., Leary, G. A., and Richards, M. J. (1962). Correlation (D) ametropia and component ametropia. Vision Research, 2, 309313.

Sorsby, A., Sheridan, M., and Leary, G. A. (1962). Refraction and its components in twins. Medical Research Council Special Report Series, No. 303. HMSO, London.

Sorsby, A., Sheridan, M., Leary, G. A., and Benjamin, B. (1960). Vision, visual acuity and ocular refractions in young men. British Medical fournal, 1, 1394-1398. 